\title{
TNF Receptor-Associated Factor 2
}

National Cancer Institute

\section{Source}

National Cancer Institute. TNFReceptor-Associated Factor 2. NCI Thesaurus. Code C17812.

TNF receptor-associated factor 2 (501 aa, $56 \mathrm{kDa}$ ) is encoded by the human TRAF2 gene. This protein is involved in antibody isotype switching, protein ubiquitination, tumor necrosis factor receptor-dependent signaling, and the regulation of apoptosis. 